\title{
Transition and the HIV risk environment
}

Tim Rhodes, Milena Simic

Social changes arising from political transition may have contributed to the spread of HIV. Successful prevention strategies require change to the risk environment as well as individual behaviour

Centre for Research on Drugs and Health Behaviour, Imperial College, Imperial College, London W6 8RP UK

Tim Rhodes researcher in public health sociology

Milena Simic research officer T Rhodes

trhodes@ imperial.ac.uk

BMJ 2005;331:220-3
Correspondence to:

Transmission of HIV, like that of other behaviourally mediated infections, is influenced by the particular environments in which risk is produced. ${ }^{12}$ The spread of HIV is shaped by variations in population behaviour and public health response, which are themselves shaped by differences in social, cultural, economic, and political condition. Prevention strategies aimed at individual behaviour may therefore only partially reduce the risk of transmission. ${ }^{3}$ We also need strategies to create the local environments and social structural conditions supportive of risk reduction by individuals and communities. Transition is a form of environmental change that can disrupt individual and community level risk reduction, weakening the capacity of public health responses. We suggest the concept of risk environment as a way of analysing the effect of large scale and abrupt social, economic, and political change in eastern Europe and the western Balkans on the spread of HIV and show how it can be used to plan a response.

\section{What is a risk environment?}

The risk environment comprises risk factors exogenous to the individual. ${ }^{45}$ It takes into account both the type and the level of environmental influence (table 1). Research into prevention of HIV highlights four types of environmental influence-physical, social, economic, and policy-at two levels. The micro-risk environment focuses on personal decisions as well as the influence of community level norms and practices. The macro-risk environment seeks to capture structural factors, such as laws, military actions, economic conditions, and wider cultural beliefs.

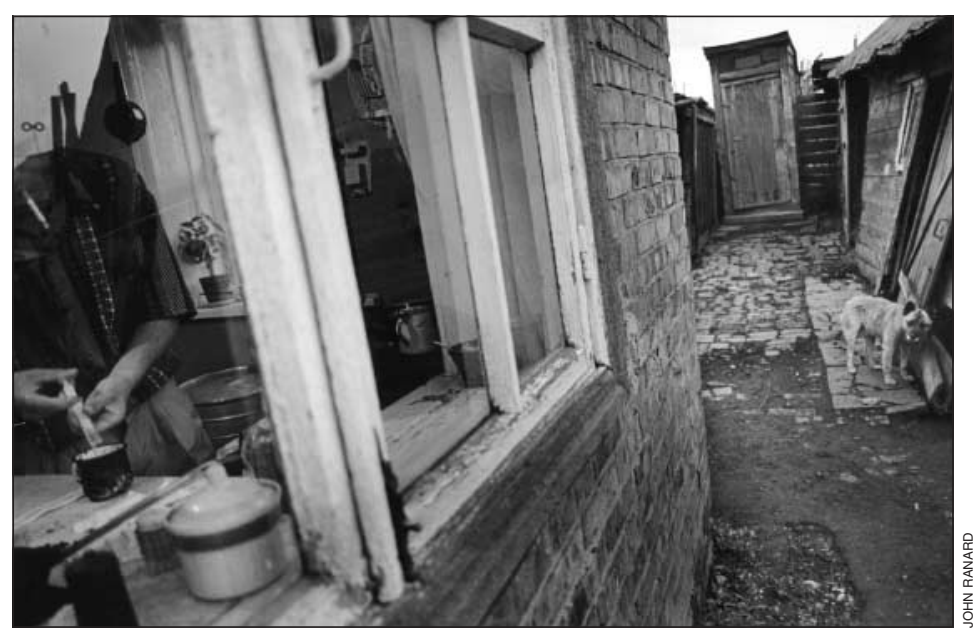

Making homemade opium tar into an injectable solution, Omsk, Russia

\section{Eastern Europe}

The rapid spread of HIV associated with drug injecting in eastern Europe since 1995 is well documented. ${ }^{1}$ Yet empirical evidence is lacking on the role of social and political transition in creating the HIV risk environment. Current evidence suggests that transition has led to economic and social dislocation, creating an environment that allows illicit drug markets, drug injecting, and related HIV risk to thrive. ${ }^{4} 67$

A macro-determinant of HIV risk in the region is the rapid increase in drug injecting. Registered injecting drug users in Russia increased at least 20 times in the eight years after political transition. ${ }^{6}$ The increase coincided with expanding transport and communication networks, which fostered migration and mixing of populations, and the growth of trade links, including in the drug and sex trades. The geographical distribution of HIV genotypes in Ukraine and Russia suggests geospatial links in transmission of HIV that are associated anecdotally with transport, trade, and tourism. ${ }^{6}$

Economic restructuring since the early 1990s has fed local informal economies, including the drug distribution and production markets. ${ }^{4}{ }^{6}$ In Ukraine, for example, the gross domestic product was around $67 \%$ lower in 2000 than it was in 1990, with the majority of the population below the poverty line. ${ }^{8}$ In this context, drug and sex markets may flourish. Local methods of drug distribution may also have contributed to transmission of the HIV virus. These include the purchase of ready filled syringes and "frontloading" (the drug solute is squirted from one syringe into the front of another with the needle removed). ${ }^{6}$

Social factors associated with transition also have a role. Rapid change may contribute to weakening of civil society and fragmentation of community responses in the face of social dislocation. Uncertainty in social and national identity may be linked with diminishing social cohesion within communities, which is exacerbated by economic hardship. ${ }^{9}$ Such conditions can weaken capacity for avoiding risk. ${ }^{910}$ Additionally, a norm of administering medicine by injection, a tradition of growing opium poppies in some areas, and a drug culture where injecting predominates has created a social environment conducive to injecting heroin. ${ }^{6}$

Though borne out of dislocation, using drugs can provide pleasure and prestige, especially in a new or uncertain consumer market (J Fitzgerald, unpublished data). The productive social value attached to drugs in eastern Europe may reflect more broadly the globalisation of western drug markets and cultures Risk of HIV infection may be an indirect feature of such social transformations. 
Education and debate

Economic transition has weakened public health infrastructures because of the removal of state subsidies, declining revenue, unemployment in the health sector, and growth in private care and self treatment. The spread of HIV in the region coincided with declining life and health expectancy, re-emerging communicable diseases, a rise in multidrug resistant tuberculosis, high levels of morbidity associated with alcohol use, and high prevalence of sexually transmitted infections. ${ }^{4}{ }^{7}$ The HIV epidemic creates demand on a fragile health system. Coverage of HIV prevention and treatment among injecting drug users is woefully inadequate. ${ }^{11}$

Additionally, tensions exist between public health and law enforcement approaches. These combine with local uncertainties about the interpretation of state drug laws, especially concerning schemes for exchanging syringes, which are sometimes seen as promoting or aiding drug use. ${ }^{5}$ Aggressive street policing has been shown to reduce opportunities for reducing risk among injecting drug users and to increase sharing of syringes. ${ }^{2}$

\section{Western Balkans}

The western Balkans includes Bosnia and Herzegovina, Serbia and Montenegro, Kosovo, Albania, and Macedonia. Official estimates suggest the prevalence of HIV infection is low (ranging from 47 cases in Kosovo to 1767 in Serbia by December 2003) and that the infection is primarily sexually transmitted, except in Serbia where drug injecting is the main route. ${ }^{12}$ Although the Balkan HIV epidemic is different from that of eastern Europe, the risk environment has similarities, including widespread poverty; mass unemployment and social insecurity; increasing human, drugs, and sex trafficking; migration associated with economic hardship and civil strife; and transitions from command economies to open markets associated with drastic reductions in health and welfare provision as well as new sex and drug markets.

The effect of conflict on vulnerability to HIV infection in the region is under-researched. Armed and ethnic conflicts have affected large sections of the Balkan population, many of whom have been displaced. In Serbia, a quarter of some city populations are internally displaced people, and there are around 700000 refugees and displaced people in a population of 8 million. ${ }^{13}$ Over 500000 people in Bosnia and Herzegovina and 300000 in Kosovo are displaced. ${ }^{12}$ Population displacement is linked with lack of access to food, shelter, and health care. ${ }^{14}$ Refugee collection centres often lack sanitation. Some are associated with sexual violence or abuse.

Regional conflicts have intersected with economic and political transition. The Yugoslavian conflicts shifted Serbia and Montenegro from a medium developed to an underdeveloped nation. ${ }^{15}$ International sanctions reportedly created "universal compulsory poverty," trapping whole social groups on state subsidies while forcing the most able into illegal economies, including human and drug trafficking. ${ }^{16}$ In 2002, the income of over half of the Serbian population was insufficient to meet basic needs. ${ }^{17}$ Economic decline in the region displaced educated economically active young people abroad. During the 1992-5 war in Bosnia, nearly half of all health workers
Table 1 Simple model of HIV risk environment in the context of transition ${ }^{5}$

\begin{tabular}{lll}
\multicolumn{1}{c}{ Micro-environment } & \multicolumn{1}{c}{ Macro-environment } \\
\hline Physical & Drug injecting sites & Trade and trafficking routes (drugs, sex, humans) \\
& Sex work sites & Labour mobility, urban and economic migration \\
& Prisons and detention centres & Geographical dispersal of population \\
& Refugee collecting and dispersal centres & \\
\hline Social & Peer and social norms & Social and cultural norms and values \\
& Community attitudes & National and cultural identity and nationalism \\
& Local policing practices & Gender and social inequalities \\
& Community health and welfare services & Stigmatisation and marginalisation of social groups \\
& & Civil society and societal infrastructure \\
\hline Economic & Cost of living and health care & Economic regulation and development \\
& Income generation & Public and health service revenue and spend \\
& Informal local economies & Employment norms and practices \\
& Economic enterprise & \\
\hline Policy & Distribution of syringes & Policies governing trade, trafficking, and migration \\
& Distribution of condoms & Laws governing drug use and syringe exchange \\
& City regulations & Laws governing sex and consent \\
& & Laws governing health, welfare, and citizen rights
\end{tabular}

left the country. Attendance at medical school fell by half, weakening capacity in health expertise. ${ }^{18}$

Sex inequalities have become particularly visible. Refugees and displaced people are often women or children whose host countries are also compromised in relation to HIV vulnerability and human rights. ${ }^{10}$ People changed sexual partner more frequently during the conflicts, ${ }^{19}$ and sex work is also linked with human trafficking in a weakening labour market. Rape was used as a weapon against ethnic populations, with 50000 women reportedly raped in Bosnia and Herzegovina and Croatia. ${ }^{20}$ Drug use also increased in the region, associated with psychological trauma from experiencing war and perceived loss of life opportunity. ${ }^{192}$

Regional conflicts connected with a history of nationalism and reproduced a culture of governance that discriminated against diversity. ${ }^{22}$ This has fed intolerance towards social groups that do not meet a national ideal. Populations of Roma, men who have sex with men, people with HIV and AIDS, refugees, and displaced people face multiple vulnerability. In Serbia, $40 \%$ of registered Roma live in refugee centres; they rarely have legal employment, lack access to public services, and often lack citizenship rights. ${ }^{23}$ Prejudice within medical communities towards men who have sex with men and people with HIV infection discourages them from seeking help ${ }^{12}$ and limits capacity to prevent the spread of HIV..$^{10}$

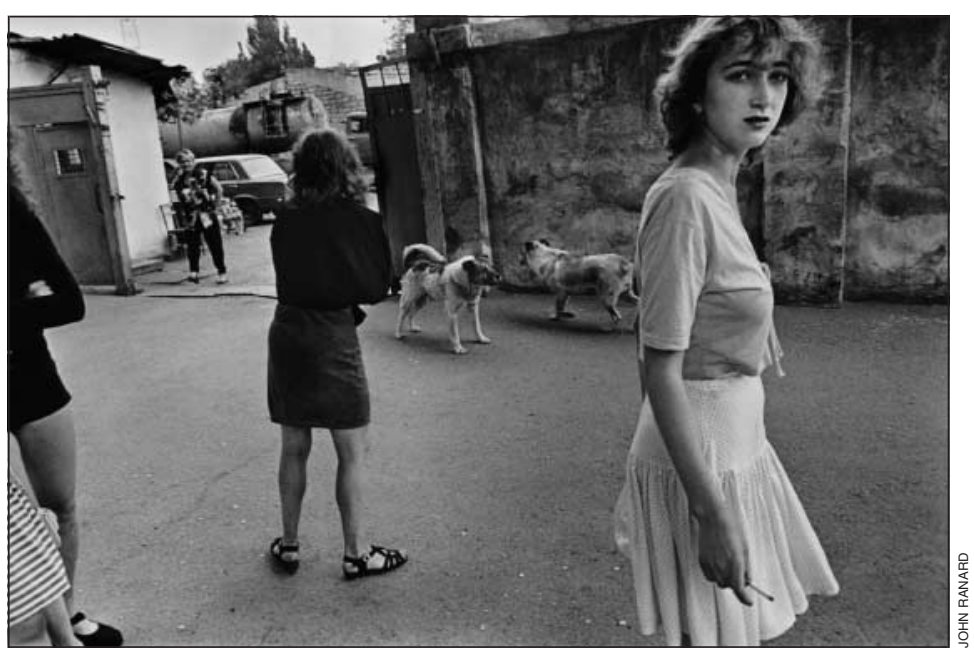

Street sex workers in Odessa, Ukraine 
Table 2 Simple model of social and structural change for preventing transmission of HIV

\begin{tabular}{lll} 
& \multicolumn{1}{c}{ Micro-environment } & \multicolumn{1}{c}{ Macro-environment } \\
\hline Physical & Supervised injecting rooms & Cross border interventions \\
& Managed sex work zones & Trade policies and trafficking interdiction \\
& Sharps disposal at injecting sites & $\begin{array}{l}\text { Condom distribution at truck stops and train stations } \\
\text { Migration and immigration policies }\end{array}$ \\
\hline Social & Peer education interventions & Media campaigns and advocacy \\
& Community action initiatives & Initiatives by faith organisations \\
& Self help initiatives & Restoring citizenship, residency, and welfare rights \\
& Community development initiatives & Structural change to health service \\
\hline Economic & Economic enterprise initiatives & National funding schemes and spending priorities \\
& Employment schemes & National health insurance schemes \\
& Free or subsidised drug treatment & Employment rights and opportunities \\
& Distribution of free syringes and condoms & \\
\hline Policy & Secondary syringe distribution & Laws promoting distribution of syringes \\
& Distribution of condoms in prisons & Laws promoting sexual safety \\
& Free voluntary HIV testing & Laws protecting against human rights abuse \\
\hline
\end{tabular}

As in Russia, the public health response in Balkan countries is vulnerable. The development of national strategies for preventing HIV infection has been displaced by other welfare pressures. In Kosovo, Albanians were deprived of health treatment and feared mistreatment in the Serb-run hospitals of Pristina. ${ }^{24} \mathrm{In}$ parts of Bosnia, the rebuilding of health care became a site for nationalistic stalemate, with all parties being obstructive. $^{25}$ The ageing health services face chronic shortage of medical equipment and medicines (including HIV test kits), increasing reliance on private pharmacies and health care, cuts in spending, and administrative upheaval in reorienting to new national boarders. The non-government sector is embryonic, especially for HIV and AIDS. HIV prevention comprises small pilot projects with short term funding. Investment in epidemiology and surveillance stalled during transition. Consequently, surveillance of HIV and AIDS can be unreliable, making the detection of HIV outbreaks difficult. ${ }^{26}$

\section{Value of risk environment approach}

The risk environment is a simple heuristic for researching multiple environmental factors that produce health risk. This framework is useful because it shifts the focus of intervention from individuals to the social situations, processes, and structures in which individuals participate.

Comparing HIV risk environments in different settings enables us to delineate the role of transition and

\section{Summary points}

Environmental conditions arising from transition may increase the risk of HIV transmission

A risk environment approach to HIV could help develop prevention and coping strategies that emphasise environmental change

Comparing HIV risk environments in different settings can help identify the role of transition and other environmental factors

A risk environment approach fosters closer linkage between epidemiology and social science and aids development of new research methods other environmental factors in the spread of HIV, thereby identifying questions for future research. The power of qualitative description rests in its capacity to generate hypotheses rather than test them, but we believe that iterative and comparative qualitative description over time will show key parallels between different risk environments.

Another advantage of the risk environment approach is that it fosters multidisciplinary research. Closer linkage between epidemiology and social sciences is crucial to understanding risk. ${ }^{910}$ The application of social epidemiology to studying HIV risk environments and transition is only just beginning. ${ }^{2}$

The approach not only helps explain the conditions that have given rise to harm but helps identify potential risk environments. Although the HIV epidemics of eastern Europe and western Balkans are different in terms of history, transmission dynamics, and prevalence, our comparative description suggests that the environmental conditions that influence the spread of the epidemic overlap. One such overlapping feature is the creation of economic and social uncertainty during transition.

\section{Implications for HIV prevention}

Study of the HIV risk environment shows that prevention strategies need to support large scale community risk avoidance as well as change individual behaviour. Table 2 shows examples of interventions fostering environmental change. These strategies focus on ameliorating the conditions underpinning increased risk of HIV as well as structural change. Examples include interventions removing legal, economic, or policy obstacles to prevention, such as creating legal access to free sterile injecting equipment without fear of arrest.

Moreover, many of the health effects of large scale social, economic, or political transition, as well as complex emergencies, are beyond the immediate reach of human prevention. This underscores the need for a broader and long term vision for health intervention that encompasses alleviation of poverty, economic reform, policy change, human rights, and community action. Equally, this emphasises the need to raise awareness of population health as a determinant of large scale social and political forces operating regionally as well as globally.

Contributors and sources: TR is a public health sociologist conducting multi-method research and HIV prevention in eastern and southeastern Europe. His expertise is in qualitative research investigating the contextual factors shaping risk behaviour. This article arose out of work documenting HIV risk in Russia and the western Balkans and drew largely on a review of published literature. TR and MS contributed to the conception and writing of the paper. TR is guarantor.

Competing interests: None declared.

1 Rhodes T, Stimson GV, Crofts N, Ball A, Dehne KL, Khodakevich L. Drug injecting, rapid HIV spread and the risk environment. AIDS 1999 13:S259-69.

2 Poundstrone KE, Strathdee SA, Celentano DD. The social epidemiology of human immunodeficiency virus/acquired immunodeficiency syndrome. Epidemiol Rev 2004;26:22-35.

Blankenship KM, Bray S, Merson MH. Structural interventions in public health. AIDS 2000;14(suppl A):S11-21.

4 Barnett T, Whiteside A. HIV/AIDS and development: case studies and a conceptual framework. Eur J Dev Res 1999;11:200-34.

5 Rhodes T. The risk environment: a framework for understanding and Rhodes T. The risk environment: a framework for unders
reducing drug-related harm. Int J Drug Policy 2002;13:85-94. 
6 Rhodes T, Ball A, Stimson GV, Kobyshcha Y, Fitch C, Pokrovsky V, et al. HIV infection associated with drug injecting in the newly independent states, eastern Europe: the social and economic context of epidemics. Addiction 1999;94:1323-36

McKee M. Substance use and social and economic transition: the need for evidence. Int J Drug Policy 2002;13:453-9.

8 European Bank for Reconstruction and Development. Transition report. energy in transition. London: EBRD, 2001.

9 Farmer P, Connors M, Simmons J. Women, poverty and AIDS: sex, drugs and structural violence. Monroe, MN: Common Courage Press, 1996.

10 Pedersen D. Political violence, ethnic conflict, and contemporary wars: broad implications for health and social well-being. Soc Sci Med 2002;55:175-90.

11 Rhodes T, Sarang A, Bobrik A, Bobkov E, Platt L. HIV transmission and HIV prevention associated with injecting drug use in the Russian Federation. Int J Drug Policy 2004:15:1-16.

12 Godinho J, Jaganjac N, Eckertz D, Renton A, Novotny T, Garbus L. HIV AIDS in the western Balkans: priorities for early prevention in high-risk environment. Washington, DC: World Bank, 2004

13 United Nations Development Programme. Building blocks for reform and recovery: mid-term report 2002-2003. Belgrade: UNDP, 2003.

14 Duff CH. Balkan briefing: Reflections on the health of a refugee population. J Epidemiol Community Health 1999;53:578-9.

15 United Nations Development Programme Human development report Yugoslavia. Belgrade: UNDP, 1997.
16 Gordy E. The culture of power in Serbia: nationalism and the destruction of Alternatives University Park, PA. Pennsylvania State University Press, 1999.

7 Ministry of Social Affairs of Republic of Serbia. poverty reduction strategy paper for Serbia. Belgrade: Ministry of Social Affairs, 2003.

18 Horton R. Croatia and Bosnia: the imprints of war: restoration. Lancet 1999;353:2223-8.

19 Carballo M, Puvacic S, Zeric D. Implications of complex emergencies, uprooting and forced migration on risk of HIV/AIDS: the case of Bosnia and Herzegovina. Twelfth World AIDS Conference, Geneva, June 1998: Abstract No 244/14139.

20 Olujic M. Embodiment of terror: gender violence in peacetime and wartime in Croatia and Bosnia and Herzegovina, Med Anthropol $Q$ 1998;12:31-50.

21 Carballo M, Smajkic A, Zeric D, Dzidowska M, Gebre-Medhin J, Van Halem J. Mental health and copying in a war situation: the case of Bosnia and Herzegovina.J Bio Soc Sci 2004;36:463-77.

22 Djilas A. A profile of Slobodan Milosevic. Foreign Affairs 1993;72:81-96.

23 European Roma Rights Centre. Roma: fundamental rights in former Yugoslavia. Budapest: ERRC, 2002.

24 Argovino T. Serbia continues to fail ethnic Albanians. Lancet 1997;350:1757.

25 Pyle GF, Thompson CR, Oreskovic S, Bagaric I. Rebuilding the healthcare system in Mostar: challenge and opportunity. Croatian Med J 1998:39:3.

26 Wong T. Rapid assessment of Serbia HIV/AIDS/STI surveillance system. Ottawa: Centre for Infectious Disease Prevention and Control, 2002.

\title{
Croatian healthcare system in transition, from the perspective of users
}

\author{
Miroslav Mastilica, Sanja Kušec
}

Reform of the Croatian healthcare system focused mainly on centralising financing, rationing services, and encouraging the provision of private health services with incentives. Although these changes may have contained costs, they have increased inequality of access to health care and proved highly unpopular with users

In Croatia, as in other countries in transition, healthcare reform was a necessary process that went alongside general changes in the political system and economy. New objectives and measures were defined in the early 1990s, adopted by the Croatian parliament, and came into force with the new Health Care Act and Health Insurance Act in 1993.

The principal motive for healthcare reform was dissatisfaction with the existing healthcare system: the government was dissatisfied with the economic inefficiency of the system, doctors were dissatisfied with their income, and people were mainly dissatisfied with access (long waiting times), the behaviour of staff, and regular shortages of drugs. ${ }^{12}$ Consequently, healthcare reform primarily focused on financing, rationing of services, and introduction of private incentives in the provision of services.

\section{Healthcare reform-objectives, measures, problems}

Centralisation of financing resulted in the establishment of a central insurance fund in 1990, responsible for implementation of health policies and financing and control of health services. New standards of insured rights were established. Compulsory health insurance covered a restricted range of health services, reducing the volume of services covered, and the list of

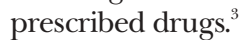

Financial management of health services was introduced to control expenditure. Health providers were contracted by the state insurance fund and paid only for providing the determined standard of services. Limiting services was thus established as a control mechanism, mainly in primary health care, and doctors became responsible for any overuse of services. Cost sharing (copayments) was introduced for almost all health services and drugs. Exemptions were made for children and students, people receiving the minimum income, the unemployed, people aged 65 or more, war veterans, people in military service, and those with chronic mental illness or communicable diseases.

Voluntary health insurance was introduced either as supplementary insurance (for higher standard or quality of care, such as for extra services and drugs excluded from the compulsory insurance plan, and for amenities) or as private health insurance (limited to the highest income groups (annual income $\geq$ US\$35 000).

Privatisation of services, as one of the main goals of health reform, took two basic forms-private practice in privately owned facilities provided by self employed doctors, and private practitioners in rented offices of public health institutions.

\section{Problems with the reforms}

Various measures aimed at cost containment-such as rationing of services, limitation of services provided, penalties for excessive prescribing or referrals, a limited list of approved drugs, reductions in health budgets, increases in copayments-have been implemented over the past 10 years in the Croatian healthcare system, but with only limited success and acceptance from providers and the public.
Department of Medical Sociology, Andrija Štampar School of Public Health, Medical

School, University of Zagreb,

Rockefellerova 4,

HR-10000 Zagreb, Croatia

Miroslav Mastilica associate professor

Department of Educational Technology, Andrija Stampar School of Public Health

Sanja Kušec master of science in public health

Correspondence to:

M Mastilica mmastil@snz.hr

BMJ 2005;331:223-7 